\title{
ORTOGRAFIA: UM ENFOQUE NAS PRÁTICAS DOCENTES
}

\author{
Ana Luzia Videira Parisotto, Patrícia Regina de Souza, Elaine Nabor de Lima² \\ Universidade Estadual Paulista - FCT/UNESP, Departamento de Educação, Presidente Prudente, SP. Órgão de \\ fomento: CNPq. E-mail: analu.videira@uol.com.br
}

\section{RESUMO}

Há muitos desafios postos ao professor para o ensino de ortografia, pois os erros dos alunos podem fornecer subsídios a respeito das hipóteses ou dos conhecimentos já adquiridos e motivar a proposição de atividades reflexivas. Nesse sentido, esta pesquisa de base qualitativa objetivou refletir sobre como o professor do 10 ao 50 ano da Rede municipal de ensino de Presidente Prudente trabalha com conteúdos ortográficos. Para tanto, analisamos os dados referentes a quatro escolas vinculadas à Secretaria de Educação do município de Presidente Prudente, no que diz respeito às respostas dos professores emitidas por meio de questionários. Os resultados iniciais apontam que, embora os docentes estejam preocupados em minimizar as dificuldades dos alunos, sanando suas dúvidas e trabalhando a partir de seus erros, a análise das respostas revela a falta de um direcionamento para que as práticas não fiquem descontextualizadas.

Palavras-chave: Formação docente, ensino de ortografia, alfabetização, escrita, pesquisa qualitativa.

\section{SPELLING: TEACHING PRACTICES IN FOCUS}

\section{ABSTRACT}

The teaching of spelling poses many challenges to teachers. Students' mistakes can provide teachers with important data regarding assumptions or acquired knowledge and motivate them to propose reflective activities to overcome these challenges. In this sense, this research, of a qualitative nature, aimed to reflect on how $1^{\text {st }}-5^{\text {th }}$-year teachers deal with spelling content at elementary schools. To this end, we analyzed data from questionnaires responded by teachers from four schools associated to the Bureau of Education of Presidente Prudente, Brazil. The analysis of preliminary results indicate that in spite of the participating teachers being intent on minimizing students' spelling difficulties, elucidating their doubts, and working on their mistakes, their teaching practices lack contextualization in this respect.

Keywords: Teacher education, teaching of spelling, literacy, writing, qualitative research. 


\section{INTRODUÇÃO}

O sistema ortográfico é complexo e causa muitas dificuldades para os alunos em processo de alfabetização. Contudo, se as práticas docentes visarem à reflexão sobre a ortografia, os alunos podem ter suas dificuldades minimizadas e a aprendizagem facilitada. Assim, o modo como o professor realiza o ensino na sala de aula pode impactar positiva ou negativamente no processo de aquisição da linguagem escrita.

Entretanto, a realidade encontrada na sala de aula vai de encontro ao que é preconizado pelas pesquisas sobre o ensino ortográfico, já que o trabalho com a ortografia não é visto com a devida importância. Vale ressaltar ainda que, muitas vezes, o professor não recebeu uma formação adequada para lidar com as especificidades do sistema ortográfico de maneira reflexiva, o que pode acarretar um ensino mais mecânico e baseado na memorização, em todas as situações de aprendizagem.

É necessário que a ortografia seja objeto de reflexão dentro da sala de aula, uma vez que, ao não ensinar a ortografia, a escola está dando margem para que existam diferenças sociais, pois sempre haverá distinção entre bons e maus usuários da língua escrita (MORAIS, 2009).

Dessa forma, a apropriação das convenções ortográficas, ao longo da escolarização, é algo imprescindível. Porém, de acordo com Cagliari e Massini- Cagliari (1999), o sistema ortográfico apresenta muitas incongruências que podem gerar dificuldades para as crianças em processo de alfabetização.

Ainda de acordo com os autores, na medida em que os alunos vão aprendendo a escrever mais e mais palavras ortograficamente, irão compreender que as relações entre sons e letras apresentam arbitrariedades que podem deixá-los na dúvida diante da escrita de determinadas palavras. Isso porque, como aponta Lemle (1999), as relações entre sons e letras do nosso alfabeto nem sempre são biunívocas, pois existem casos de poliandria e poligamia que se caracterizam por sons casados com letras diferentes segundo a sua posição e letras que casam com diferentes sons.

Faraco (1994, p. 9) enfatiza que, "O professor alfabetizador precisa, entre outras coisas, ter um bom conhecimento da organização do sistema gráfico para poder melhor sistematizar seu ensino" porque, só assim, segundo o autor, o professor poderá compreender as dificuldades ortográficas que seus alunos apresentam e, dessa forma, poderá auxiliá-los para que superem tais dificuldades.

Segundo Morais (2009), é fundamental que o professor compreenda o que é regular e irregular na ortografia, pois será preciso estabelecer diferentes estratégias de ensino e de 
aprendizagem, já que os erros são de naturezas distintas. Levando em conta essa distinção, o professor terá claro o que o aluno precisa memorizar e o que precisa compreender.

Morais (2007) afirma que, quando um aprendiz passa a escrever corretamente é sinal de que passou a observar os aspectos diversos do "sub-sistemas" de sua língua, ou seja, passou a tratá-la como um objeto de conhecimento. Sendo assim, o autor acredita que a ortografia, por si só, é um objeto de conhecimento e embora ela seja uma convenção social, o aprendiz não vai aprendê-la de forma passiva.

Nesse sentido, as práticas docentes devem ser focalizadas, pois elas têm refletido de maneira contundente no modo como os alunos encaram o processo de aquisição do sistema ortográfico.

Conforme Morais (2009), as práticas com relação à ortografia nas escolas têm que ser reformuladas. Para tanto, é preciso levar em conta três aspectos: a criança necessita conviver com modelos nos quais apareça a norma ortográfica, ou seja, ter um grande convívio com materiais impressos; o professor deve promover situações de ensino-aprendizagem que levem à explicitação dos conhecimentos infantis sobre a ortografia; o professor precisa definir metas ou expectativas para o rendimento ortográfico de seus alunos ao longo da escolaridade. De acordo com o autor:

Para podermos ajudar nossos alunos na reconstrução de cada conteúdo do currículo escolar, precisamos aprofundar continuamente os saberes que temos a respeito do objeto ou tema a ser ensinado [...] e sobre o modo como o aprendiz concebe [...] esse objeto a ser ensinado. (2009, p.10).

Assim, a questão norteadora que se coloca para este artigo é: qual a metodologia utilizada pelos professores pesquisados com relação ao ensino de ortografia? Por essa questão central perpassam outras: as dificuldades dos alunos são levadas em conta no ensino da ortografia? 0 dicionário é utilizado como instrumento de pesquisa para a aprendizagem das regularidades e a fixação das irregularidades da norma ortográfica?

Neste artigo serão apresentados alguns dados de uma pesquisa maior cujo objetivo foi refletir sobre a formação do professor dos anos iniciais do Ensino Fundamental para superação do fracasso escolar em língua materna. O recorte para a apresentação dos dados dar-se-á em função da delimitação de aspectos relacionados ao ensino de ortografia. Dessa forma, nosso objetivo para este artigo foi refletir sobre como o professor do 1ㅇ ao 5을 ano da Rede municipal de ensino de Presidente Prudente trabalha com ortografia. 


\section{METODOLOGIA}

Nesta investigação utilizamos a abordagem qualitativa, descrevendo e analisando os fenômenos que estão impregnados dos significados que o contexto social thes concede. Dessa forma, os dados foram obtidos por meio de questionários aplicados a professores e gestores, bem como por análise documental. O projeto foi aprovado pelo Comitê de Ética em Pesquisa da Faculdade de Ciências e Tecnologia - Unesp - Presidente Prudente (Protocolo 947.980), em 06/02/2015.

A nossa amostra foi composta por professores e gestores de vinte e três escolas municipais vinculadas à Secretaria de Educação do Município de Presidente Prudente. Os questionários destinados aos docentes foram utilizados para caracterizar o perfil pessoal, profissional e o teórico-metodológico do professor que leciona nos anos iniciais do ensino fundamental, bem como as dificuldades enfrentadas cotidianamente no ensino de língua materna, quais são as práticas formativas que consideram eficazes e como avaliam a contribuição da gestão escolar, com relação à superação do fracasso escolar em língua materna. No que concerne aos gestores, o questionário destinado a esse profissional abordou questões relativas às práticas formativas que consideram eficazes e à contribuição da gestão escolar no sentido de propor ações para a superação do fracasso escolar.

Os dados estão sendo tabulados e analisados à luz da análise de conteúdo (BARDIN, 2011) e do referencial teórico voltado para o ensino de língua materna e formação docente (GERALDI, 2002; KOCH E TRAVAGLIA, 2008; KOCH, 2001; IMBERNÓN, 2005; MORAIS, 2009; TARDIF E LESSARD, 2008; UNESCO, 2004).

Para este artigo apresentaremos somente os resultados referentes às respostas emitidas pelos professores de quatro escolas vinculadas à Secretaria de Educação do Município de Presidente Prudente sobre a metodologia utilizada por eles para o ensino de ortografia.

\section{RESULTADOS}

Nossa pesquisa ainda está em andamento, pois, de acordo com os objetivos previstos, trabalharemos com o ensino de língua materna, observando vários aspectos que podem contribuir para o fracasso escolar. Contudo, neste artigo, evidenciaremos as práticas docentes com relação ao ensino de ortografia. Assim, selecionamos uma pergunta do questionário que foi respondido pelos professores a qual ia ao encontro do que nos propusemos para este trabalho. 
Desse modo, no Quadro 1, a seguir, apresentamos as respostas de professores de quatro escolas, totalizando vinte e um docentes, sendo seis professores da escola I, cinco da escola II, quatro da escola III e seis da escola IV. Em seguida, apresentamos um gráfico com as categorias de análise que emergiram das respostas emitidas pelos docentes pesquisados.

Quadro 1. Como você trabalha a ortografia?

\begin{tabular}{|l|l|}
\hline Docentes & \multicolumn{1}{|c|}{ Respostas } \\
\hline P1 & $\begin{array}{l}\text { De forma Contextualizada, de acordo com os textos trabalhados. } \\
\text { Livro: Ler e Escrever, livro didático, etc. }\end{array}$ \\
\hline P2 & Por meio de Letras, sílabas, sílabas simples, sílabas complexas, sons, uso do dicionário. \\
\hline P3 & Oralmente e no momento em que escrevem e fazemos a correção coletiva. \\
\hline P4 & Conceitos e exercícios diversos, corrigindo-os em cada erro encontrado. \\
\hline P5 & Oralmente e dentro das atividades propostas. \\
\hline P6 & Oralmente e dentro das atividades propostas. \\
\hline P7 & Durante a construção das famílias silábicas e a análise fonológica das letras. \\
\hline P8 & Durante a apresentação das famílias silábicas e análise fonológica. \\
\hline P9 & De acordo com o texto e a gramática trabalhada. \\
\hline P10 & Correção das produções em casos específicos, as normas no coletivo. \\
\hline P11 & $\begin{array}{l}\text { Apresento o texto e faço com que os alunos retirem do texto sua ortografia. Onde se } \\
\text { encontra a dificuldade }\end{array}$ \\
\hline P12 & Através da escrita de frases e textos. Leitura pesquisa no dicionário \\
\hline P13 & Não respondeu \\
\hline P14 & pesquisas, reescritas, leituras \\
\hline P15 & Com material didático e paradidático. Com base no cotidiano dos alunos, suas vivências \\
\hline P16 & $\begin{array}{l}\text { Comparações de escritas, correções individualizadas e coletivas na lousa. Utilizo o livro } \\
\text { didático e complemento com o xérox. }\end{array}$ \\
\hline P17 & Abordo a dificuldade dentro do texto construído pelo aluno. \\
\hline P18 & $\begin{array}{l}\text { Como é o primeiro ano, trabalho a escrita das palavras e quando aparecem sílabas } \\
\text { complexas,eu ensino de forma lúdica para que eles fixem, mas sem muita cobrança. }\end{array}$ \\
\hline P19 & $\begin{array}{l}\text { Caça-palavras. Livro didático, cruzadinhas, leitura de diferentes textos, produções de texto } \\
\text { para correção ortográfica, ditado. }\end{array}$ \\
\hline P20 & $\begin{array}{l}\text { A partir de um texto destacar as regularidades e irregularidades das escritas das palavras e } \\
\text { posteriormente aplicar exercícios de fixação e pesquisa. }\end{array}$ \\
\hline P21 & Uma coisa que eles pecam muito, sempre temos que auxiliar. \\
\hline
\end{tabular}




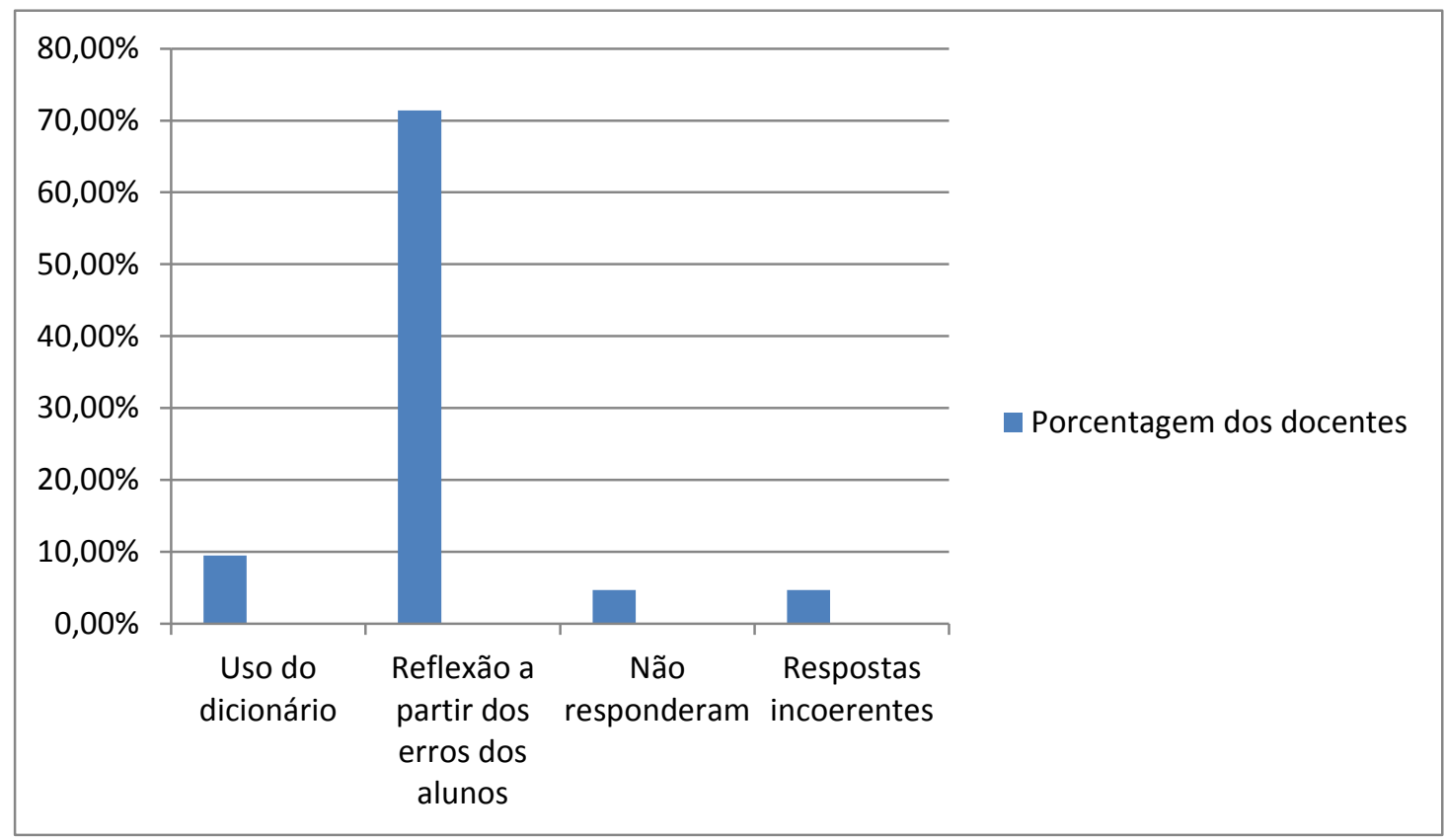

Gráfico I. Categorias de análise

Fonte: Dados organizados pelas autoras, com base nos resultados parciais da pesquisa.

\section{DISCUSSÃO}

Com relação ao ensino de ortografia, o que se constata é que as práticas docentes são diversificadas. É possível perceber que grande parte dos docentes, em sua prática pedagógica, contempla aspectos que são benéficos no que se refere à aprendizagem dos alunos. Inclusive, houve um professor que destacou levar em consideração, no que tange ao ensino de ortografia, as regularidades e as irregularidades da língua. Nessa perspectiva, Cagliari e Massini-Cagliari (1999, p. 77) destacam que "entender o que é a ortografia, como funciona e até mesmo a sua história é importante para todos, principalmente para a escola e, de modo especial, para o professor alfabetizador e seus alunos".

Entretanto, também é possível evidenciar que a ortografia ainda é um conteúdo que causa insegurança para determinados professores. Algo que vai ao encontro disso é o fato de um professor que atua no 40 ano do ensino fundamental não ter respondido como trabalha com o sistema ortográfico na sala de aula e de outro docente não ter respondido a pergunta de maneira coerente com o que foi solicitado. Por isso, Cagliari (2009, p. 10) enfatiza que "mais do que os vários outros tipos de professores, os alfabetizadores precisam de uma formação especial, mais sólida e sofisticada, dada a importância e a complexidade de seu trabalho".

No que diz respeito ao uso do dicionário, apenas $9,5 \%$ dos professores focalizados responderam que o utilizam como instrumento didático para o ensino de ortografia. De acordo com Morais (2009), o uso do dicionário em sala de aula é fundamental, uma vez que, a partir dele, 
é possível que o aluno sane suas dificuldades com relação à escrita das palavras. Além disso, o autor enfatiza que, o uso do dicionário na sala de aula é importante na medida em que pode ajudar os alunos na memorização das palavras irregulares, já que estas não possuem regras subjacentes e, portanto, devem ser memorizadas.

Com relação ao erro dos alunos, $71,4 \%$ dos professores utilizam-no como objeto de reflexão sobre a ortografia, o que é essencial para que os alunos possam entender e se apropriar do sistema ortográfico. Entretanto, Morais (2009, p. 73) explica que o professor deve semear a dúvida nos alunos. Não se limitando a esperar que surjam dúvidas por parte dos discentes, mas plantando dúvidas frequentemente. Isso para que, de forma autônoma, eles desenvolvam a capacidade de "[...] antecipar as possíveis fontes de erro que enfrentam quando escrevem".

\section{CONCLUSÃO}

Diante do exposto, destacamos que uma parcela dos professores ainda parece se sentir insegura com relação ao ensino de ortografia, além disso destaca-se a necessidade de um embasamento teórico que subsidie sua prática pedagógica, pois apesar de os docentes estarem se preocupando em minimizar as dificuldades dos alunos, sanando suas dúvidas e trabalhando a partir de seus erros, a análise das respostas revela que falta um direcionamento para que as práticas não fiquem descontextualizadas.

Nesta perspectiva, o ensino da ortografia não deve se restringir apenas a práticas eficazes, pois o professor deve ter um suporte teórico que o faça compreender o sistema linguístico, uma vez que o domínio do conteúdo é fundamental para que o docente sistematize o ensino da norma ortográfica, levando em conta o avanço na escolaridade e as peculiaridades da língua, como é o caso das regularidades e as irregularidades do sistema ortográfico.

Portanto, destacamos a relevância da participação dos docentes em cursos de aperfeiçoamento e a importância de uma formação continuada que dê subsídios para as práticas pedagógicas em sala de aula.

\section{REFERÊNCIAS}

CAGLIARI, L. C.; MASSINI-CAGLIARI, G. Diante das letras: a escrita na alfabetização. Campinas/SP: Mercado de Letras, 1999.

CAGLIARI, L. C. Alfabetização \& Linguística. São Paulo: Scipione, 2009.

FARACO, C. A. Escrita e alfabetização. 2. ed. São Paulo: Contexto, 1994. 
GERALDI, J. W. A prática da leitura na escola. In: (org). 0 texto na sala de aula. São Paulo: Ática, 2002.

IMBERNÓN, F. Formação docente e profissional: formar-se para a mudança e a incerteza. São Paulo: Cortez, 2005.

KOCH, I. V. ; TRAVAGLIA, L. C. A coerência textual. 4 ed. São Paulo: Contexto, 2008.

KOCH, I. V. A coesão textual. 15 ed. São Paulo: Contexto, 2001.

LEMLE, M. Guia teórico do alfabetizador. São Paulo: Ática, 1999.

MORAIS, A. G. Ortografia: ensinar e aprender. 5. ed. São Paulo: Ática, 2009.

MORAIS, A. G. (org.). O aprendizado da ortografia. 3. ed. Belo Horizonte: Autêntica, 2007

TARDIF, M. ; LESSARD, C. (org.) O ofício do professor. São Paulo: Vozes, 2008.

UNESCO. O perfil dos professores brasileiros: o que fazem, o que pensam, o que almejam. São Paulo: Moderna, 2004. 